\title{
Monetary Policy in Saudi Arabia: A Taylor-Rule Analysis
}

\author{
Abdullah Hussein Almounsor ${ }^{1}$ \\ ${ }^{1}$ Faculty of Administrative and Financial Sciences, Albaha University, Saudi Arabia \\ Correspondence: Abdullah Hussein Almounsor, Faculty of Administrative and Financial Sciences, Albaha \\ University, Saudi Arabia. Tel: 966-50-149-1209. E-mail: aalmounsor@bu.edu.sa
}

Received: December 22, 2014

Accepted: January 12, 2015

Online Published: February 25, 2015

doi:10.5539/ijef.v7n3p144

URL: http://dx.doi.org/10.5539/ijef.v7n3p144

\begin{abstract}
This paper assesses the stance of actual monetary policy in Saudi Arabia relative to a benchmark Taylor-rule calibration of short-term interest rates. In addition, the reaction function of monetary policy in Saudi Arabia is estimated empirically to understand the behavior of interest rates using an augmented Taylor-rule equation. The results indicates that the Saudi monetary authorities do not follow the Taylor-rule in any strict way. The actual stance of monetary policy is found to be tight in the early period of analysis, but found to be loose since 2007 , relative to the calibration outcomes. Empirically, it appears that the Federal Funds Rate is the most significant factor affecting the behavior of Saudi interest rate, given the fixed exchange rate with the USD. However, there seems to be a modest accommodation of monetary policy to productivity growth, diversification efforts, and the need for increased financial intermediation over time.
\end{abstract}

Keywords: monetary policy, Taylor-rule, Saudi Arabia

\section{Introduction}

Revolutionary thinking of modern economic theory has underscored the importance of monetary stability for improved macroeconomic outcomes. In this literature, it is postulated that rule-based policymaking is superior to discretionary decisions when conducting monetary policy. In 1993, the Taylor rule emerged as a prominent tool for modelling and understanding the behavior of monetary policy, where monetary policy is represented by changes in short-term interest rates.

The Taylor (1993) rule is a simple monetary policy tool linking the level of interest rate to deviations of inflation from its target and deviations of output from its potential. In other words, the central bank's policy should react to changes in fundamentals; namely inflation and output, to help maintain macro stability. While the rule was initially proposed to illustrate the behavior of monetary policy conducted by the US FED, it has become a popular tool for assessing monetary policy stance in both advanced economies and emerging market economies (EMEs) (Hofmann \& Bogdanova, 2012).

As the largest open economy in Middle East and the largest oil producer and exporter internationally, Saudi Arabia faces challenges in maintaining macro stability necessary for improved economic performance. In this regard, monetary policy in Saudi Arabia, conducted by the Saudi Arabian Monetary Policy (SAMA), should play an important role during business cycles to smooth fluctuations in the fundamentals specified in the Taylor rule and manage system liquidity.

However, Saudi Arabia maintains a fixed exchange rate regime pegging the Riyal to the USD with the exchange rate as the nominal anchor. While SAMA must keep close watch on the US Federal Funds Rate (FFR) to minimize pressure on the exchange rate, its mandate clearly emphasizes considerations such as containing inflation and accommodating domestic demand as necessary. According to SAMA, the objectives of monetary policy in Saudi Arabia are "Maintaining stability of the price level, including the exchange rate of the Riyal" and "Maintaining stability and development of the financial sector ... subject to strong supervision and control that will prevent sharp fluctuations in interest rates that may affect economic activity".

This paper calibrates a counterfactual Taylor-rule type monetary policy and compares actual interest rate levels in Saudi Arabia to those calibrated using the Taylor model, following the specification of Taylor (1993). In addition, the paper models the reaction function of the monetary authorities empirically in order to understand the factors that drive monetary policy behavior in Saudi Arabia over time. To my knowledge, this is the first study of its kind to assess monetary policy stance in Saudi Arabia relative to the Taylor rule and model monetary 
policy behavior econometrically at the same time.

This work has three main contributions to the literature. First, it fills the gaps in the literature on monetary policy and the Taylor rule in Saudi Arabia as a pioneering study in the area. Second, the paper augments the original Taylor rule by empirically introducing the effect of foreign financial markets, namely the other side of the exchange rate peg (USD), through movements of the Federal Funds rate.

Third, the behavior of monetary policy with a fixed exchange rate regime may substantially differ from that suggested by the Taylor rule; an issue that has not received much attention in previous studies. The monetary policy target in EMEs with pegged exchange rate regimes may be the exchange rate itself, and movements in short term interest rates may be used to protect the peg regardless of movements in the fundamentals.

The simulation results suggests that the behavior of the Saudi monetary authorities has a similar pattern to that generated by a calibration of the Taylor-rule. This may suggest an important correlation between Saudi and US business cycles. However, when comparing the levels of observed and simulated interest rates, monetary policy in Saudi Arabia seems tighter during (1984-1990, 1997-2002) than suggested by the Taylor-rule. On the other hand, the monetary policy stance in Saudi Arabia became looser during (1991-1996) and since the onset of the subprime mortgage (2007-2013) than it would have been, compared to the calibrated model outcomes.

Empirically, external factors (mostly the USD interest rate) are found to play a larger role in determining the Saudi interest rate than internal factors (the economic fundamentals of real output and inflation). However, there is a modest reaction of monetary policy in Saudi Arabia to accommodate productivity growth, increased financial intermediation, and diversification efforts, after controlling for other factors.

This paper is organized as follows. Section I provides a theoretical background on the Taylor rule monetary policy and presents some literature review. In section II, the methodology of calibration and empirical estimation is presented. Section III provides a discussion of the main findings emerging from the analysis. The concluding remarks and suggestions for future research appear in Section IV.

\section{Taylor Rule Literature}

In his seminal work, Taylor (1993) proposed a simple monetary policy rule to describe the behavior of the Federal Funds Rate in the US. The rule is an equation linking the nominal policy rate of the central bank mechanically and linearly to deviation of the inflation rate from its objective, and to the deviation of real output from its potential level. In more detail, the full-fledged instrument rule for monetary policy includes setting the interest rate equal to an 'equilibrium' real rate plus current inflation, and a weighted average of the central Banks's reaction to deviation of contemporaneous inflation from its target level or contemporaneous output from the full employment level.

As suggested by Taylor (1993), the response of monetary authorities would be raising the interest rate whenever inflation exceeds its objective or whenever output gap is positive (output exceeds its potential full employment level). Assigning equal weights to the inflation and output gap (0.5) and assuming an inflation target of 2 percent, Taylor (1993) finds that the representative policy rule traces actual momentary policy of the US FED very closely. Many researchers, following Taylor (1993) have used the rule to assess monetary policy stances and estimate the reaction function of the interest rate in both advanced economies and EMEs.

Malik and Ahmed (2010) have estimated the Taylor rule for Pakistan and compared it to actual historical levels of interest rate during 1991-2005. In addition, they have undertaken counterfactual simulation to investigate whether following the Taylor rule would have improved macroeconomic performance in Pakistan. According to their findings, monetary policy in Pakistan had consistently deviated from the Taylor, and inflation and output only explain one fourth of variations in interest rates. However, the counterfactual simulation results suggests that macroeconomic performance would have improved had the monetary authorities followed the Taylor rule.

Hofmann and Bogdanova (2012) have computed the Taylor rule benchmarks for the global aggregates, and advanced and emerging market economies, using quarterly data from 1995 to the second quarter of 2012. Their results reveal that policy rates were consistent with that of the Taylor rule up until the early 2000s, but a global deviation of policy rates from the Taylor rule thereafter. In particular, policy rates since 2003 have been below those implied by the Taylor rule. The authors argue that this deviation is driven by emerging market economies. According to them, the deviation is justified by two reasons: an asymmetric reaction of monetary policy to the different stages of the financial crisis in core advanced economies, and resistance to undesired capital flows and exchange rate movements in other countries, especially emerging market economies. In addition, the Taylor rule might have a downward bias during financial booms and upward bias during financial busts. Moreover, changes in the reserve requirement and other monetary policy instruments are not taken into account in the Taylor rule, 
which is another explanation of the observed deviation, as indicated by Hofmann and Bogdanova (2012).

Kindall and Ng (2013) analyze monetary policy behavior in the US, New Zealand and Australia using the Taylor rule since the early 1990s. Their conclusion is that monetary policy behavior in response to inflation and output gaps is similar in the three countries. Helmi (2012) estimates monetary policy reaction function using the Taylor rule for two sets of MENA countries: the inflation targeting countries (Turkey and Israel) and the exchange rate target countries (Jordan and Moroco). The findings of this paper suggest that the central banks in Turkey, Israel, and Morocco focus on stabilizing inflation while the monetary authorities in Jordan focus on stabilizing the output gap. In addition, there is a significant effect of foreign interest rate on setting domestic interest rate in Turkey. When adding the exchange rate effect, the study finds an important and significant influence on domestic interest rates in all countries of the sample. Overall, the author argues that the behavior of monetary policy in the sample countries can be described by the simple Taylor rule.

While the Taylor rule is useful in providing an analytical framework that helps monetary authorities in their decision making process, Taylor (1993) cautions central banks not to blindly implement this instrument rule. Rather, discretion should be applied depending on the different situations that prevail (Ncube \& Tshuma, 2010).

\section{Methodology}

There are two ways to undertake Taylor-type rules analysis of monetary policy. First, through model simulations whereby the optimal weights are those that minimize a loss function defined over the trade-off between fluctuations in inflation and output. The second approach is through direct empirical estimation of a Taylor-type rule over a chosen sample period and extending the analysis to derive a Taylor-rule induced policy rate.

The proposed Taylor (1993) rule takes the following form:

$$
i=r *+\pi *+\alpha(\pi-\pi *)+\beta y
$$

where $i$ is the nominal policy rate, $r^{*}$ is the long-run or equilibrium real rate of interest, $\pi^{*}$ is the central bank's inflation objective, $\pi$ is the current period inflation rate, and $y$ is the current period output gap. The term $\left(\pi-\pi^{*}\right)$ represents fluctuations of the inflation rate from central bank's objective rate, and the term $(y)$ is the output gap representing fluctuations of current output relative to is full employment level (potential). In his original model applied on the US economy, Taylor (1993) puts a weight of 1.5 for the inflation coefficient and 0.5 for the output gap coefficient. In the model, both $\alpha$ and $\beta$ take a positive sign; the central bank raises short-term interest rate in response to either rising inflation relative to the target or an overheating level of output compared to the potential.

This paper uses the original Taylor-rule simulation approach to assess the stance of monetary policy in Saudi Arabia by calibrating the Taylor rule rate of interest and comparing it to the actual interest rate (equation 1). In addition, the paper analyses the behavior of monetary policy empirically to approximate the actual response of monetary authorities to changing economic conditions, using an augmented Taylor-rule equation.

The augmented Taylor-rule takes into account the characteristics of Saudi Arabia in that the central bank maintains a fixed exchange rate against the USD. As such, the model includes the effect of the US Federal Funds Rate as well as the real effective exchange rate (REER) as determinants of the policy rate in Saudi Arabia. In addition, the augmented model takes into account structural changes in the Saudi economy that may affect monetary policy decisions over time. These include continuous reforms in the financial sector, greater diversification efforts, liberalization of trade, and improvement in the investment climate.

The augmented Taylor-rule for Saudi Arabia is specified in the following way:

$$
i=r^{*}+\pi *+\alpha\left(\pi-\pi^{*}\right)+\beta y+\delta F F R+\lambda \text { REER }+\gamma \text { Trend }+\gamma
$$

Where $i$ is the nominal short term interest rate in Saudi Arabia, the original variables are the same as those suggested by Taylor (1993) and shown in equation (1), FFR is US Federal Funds Rate (FFR); REER is the real effective exchange rate; Trend is a time trend to capture the effects structural changes leading to productivity growth, increased financial intermediation, liberalization of trade and investment, and increasing efforts of diversification; and $\gamma$ is the error term. Another justification for including the Trend as an independent variable is that the Saudi interest rates is stationary with a constant term and a linear trend at a 5 percent level of significance.

\section{Data}

The dependent variable in equation (2) is the Saudi 3-month interbank offered deposit rate (i), representing the policy rate and taken from SAMA. The long-run equilibrium real interest rate $\left(r^{*}\right)$ is calculated as the difference between the average 3-month interbank rate and the average inflation rate, following Kozicki (1999), Clarida, 
Galí and Gertler (2000) and Judd and Rudebusch (1998). The inflation rate $(\pi)$ is the annual change in the CPI as provided by SAMA. The objective rate of inflation $\left(\pi^{*}\right)$ is calculated as Hodrick Prescott (HP) Filter series, with a smoothing parameter of 100 for annual data, following Hofman \& Bogdanova (2012). As in Helmi (2011) and Ncube and Tshuma (2010), the output gap is calculated as the difference between log real GDP and the HP Filter level of GDP (or potential GDP), with a smoothing parameter of 100. The data on the actual level of real GDP is taken from SAMA. The Federal Funds Rate (FFR) is taken directly from the data of the Board of Governors of the Federal Reserve System. The real effective exchange rate (REER) is taken directly from the International Financial Statistics (IFS) database of the IMF, but transformed to $1999=100$ to be consistent with the basing of inflation and real GDP data. The Trend is a time trend variable.

\section{Discussion of Results}

The first part of the analysis discusses the calibration of the Taylor-rule based on the original Taylor (1993) specification (equation 1) and considering the same parameters of (1.5) for inflation deviations and (0.5) for real output deviations from their desired levels. As such, a comparison becomes possible between the actual level of interest rate in Saudi Arabia and the model-based level of interest rate (that derived from the Taylor-rule).

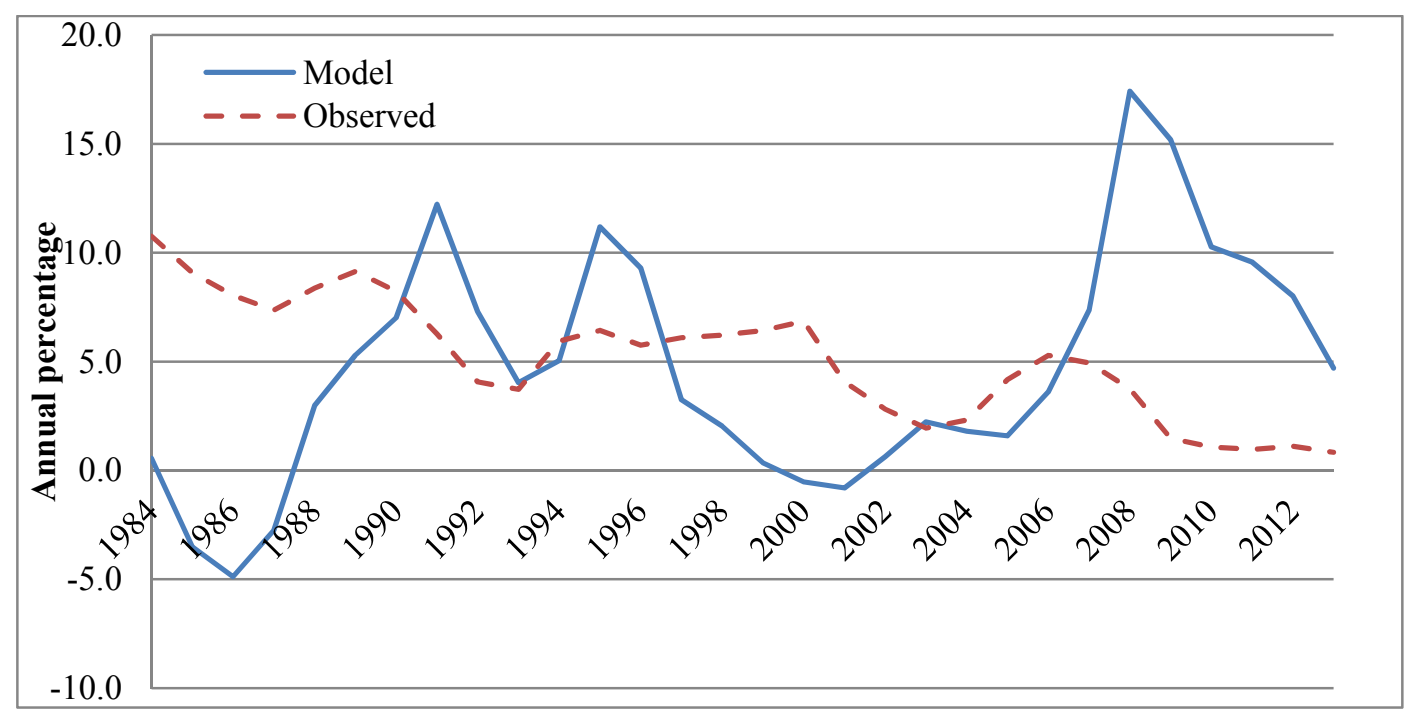

Figure 1. Model-based vs observed interest rates (1984-2013)

As seen in Figure 1, the direction of monetary policy in Saudi Arabia over the sample period appears of some proximity to that suggested by Taylor rule. With a few exceptions, the patterns of the actual level of interest rate and that induced by the model appear correlated throughout most of the analysis.

However, in the early period of analysis (1984-1990) and between (1997-2002), the actual level of the policy rate in Saudi Arabia seems higher than that suggested by the calibrated model. This implies that the actual monetary policy stance during that period was actually tighter than it should have been if the monetary authorities were following the Taylor-rule. During that period, inflation was extremely low (average -0.7 percent) and output gap was negative (average of -0.5 percent). Hence, the calibrated Taylor-rule suggested lower levels of interest rates in response to those variables.

On the contrary, the monetary policy stance appears to have been loose relative to the stance implied by the Taylor rule during 1991-1996, and between 2007-2013. During these periods, the average inflation rate increased especially during 2007-2013 (average of 5.5 percent; with 10 percent inflation for 2008 alone). In addition, the output gap turned positive (average of about 0.2 percent) during that period. The increasing inflation and the positive output gaps indicate the need for a tight monetary policy stance to counter those changes. Hence, the calibrated Taylor-rule interest rate appeared higher than the observed Saudi interest rate in order to address the differential of inflation and output from their desired levels. This indicates that actual monetary policy in Saudi Arabia was loose during that period compared to the model- simulated interest rate.

Overall, with minor exceptions, monetary policy in Saudi Arabia appears to have been tight during the first period of the analysis and loose in the recent years (2007-2013), relative to behavior implied by the Taylor-rule. 
The magnitude of level difference between the two interest rates during (2007-2013) is larger and may imply greater reliance of the monetary authorities on other monetary policy instruments such as the reserve requirements, liquidity management facilities, tight guidelines for bank credit, and intervention in foreign exchange markets. Indeed, during the crisis period, SAMA cut the reserve requirement at several rounds, guaranteed deposits and inter-bank liabilities, and placed long-term deposits with commercial banks to ensure sufficient liquidity (Almounsor, 2010).

Several modifications were applied to the Taylor rule parameters to assess the sensitivity of calibrated interest rates, but the results do not appear seemingly different from those produced by following the strict interpretation of the original rule. Even when including an interest rate smoothing parameter, the result still point to the same conclusion but with a relatively smaller divergence and a smaller gap between the two interest rates toward the end of the sample period (2007-2013).

The second part of the analysis discusses the econometric results of the driving factors affecting the behavior of actual monetary policy in Saudi Arabia based on equation (2). Prior to carrying out the econometric exercise, Augmented Dickey Fuller (ADF) unit root tests were applied on the variables in the equation. All variables appeared stationary at different significance levels; the Saudi interest rate (interest) and the FFR are stationary with both a constant and a linear trend; the other variables are stationary with only the constant term. The number of lags is based on the Schwartz Information Criterion. The ADF statistics and probabilities are shown in Table 1.

Table 1. Unit root tests

\begin{tabular}{lll}
\hline Variable & ADF score & Probability \\
\hline Interest & -4.97 & $0.0022^{* *}$ \\
Inf_Diff & -3.12 & $0.0356^{*}$ \\
Output gap & -3.65 & $0.0101^{*}$ \\
FFR_Dollar & -4.17 & $0.0133^{*}$ \\
REER & -3.19 & $0.0305^{*}$ \\
\hline
\end{tabular}

Note. $* * *, * *, *$ denote the significance at the levels 1,5 , and 10 percent, respectively.

Table 2. Dependent variable: Saudi interest rate

\begin{tabular}{llllll}
\hline Coefficient & $(1)$ & $(2)$ & $(3)$ & $(4)$ & $(5)$ \\
\hline Intercept & 1.08 & 1.94 & 2.044 & 2.025 & 2.03 \\
& $(0.000)^{* * *}$ & $(0.005)^{* * *}$ & $(0.002)^{* * *}$ & $(0.001)^{* * * *}$ & $(0.001)^{* * *}$ \\
Inf_Diff & 0.026 & 0.027 & 0.009 & & \\
& $(0.622)$ & $(0.641)$ & $(0.859)$ & & \\
Output_gap & -0.124 & -0.163 & & -0.127 & \\
& $(0.639)$ & $(0.553)$ & & $(0.518)$ & \\
FFR_Dollar & 0.92 & 0.85 & 0.855 & 0.851 & 0.855 \\
& $(0.000)^{* * *}$ & $(0.000)^{* * *}$ & $(0.000)^{* * *}$ & $(0.000)^{* * *}$ & $(0.000)^{* * *}$ \\
REER & -0.016 & -0.007 & & & \\
& $(0.227)$ & $(0.639)$ & & & \\
Trend & & 0.028 & -0.032 & -0.032 & $0.032-$ \\
& & $(0.188)$ & $(0.097)^{*}$ & $(0.106)$ & $(0.098)^{*}$ \\
Adjusted $\mathrm{R}^{2}$ & 0.98 & 0.98 & 0.98 & 0.98 & 0.98 \\
F-stat & 285 & 238 & 415 & 420 & 645 \\
DW & 1.86 & 1.86 & 1.86 & 1.95 & 1.9 \\
Obs. & 30 & 30 & 30 & 30 & 30 \\
\hline
\end{tabular}

Note. The symbols $* * *, * *, *$ denote the significance at the levels 1,5 , and 10 percent, respectively. P-values appear in parentheses with White heteroskedasticity consistent standard errors.

Several variants of equation 2 were estimated to assess the robustness of different specifications. Also, relevant diagnostic tests were performed to check the validity of the estimates. First, joint-significance Wald Tests were performed to test the significance of all variables jointly in the model. The score indicates that all coefficients are together significantly different from zero and are jointly significant. Second, the residuals look well behaved and 
mean-reverting around zero as shown in Figure A1 in the Appendix. Third, serial correlation tests of the residuals were conducted and showed no presence of autocorrelation in the residuals as indicated by the DW statistics. A final diagnostic test for multicollinearity was done by taking correlations across variables, and it indicates no presence of multicollinearity among the independent variables.

The results indicate that the deviation of inflation from its target and the deviation of real GDP from its potential level are insignificant determinants of the Saudi interest rate. In other words, monetary policy in Saudi Arabia, represented by the short-term interest rate, does not respond in a significant way to the deviations in inflation and real output from their desired levels. This result is consistent across different specifications. Intuitively, when the fixed exchange rate is the nominal anchor for monetary policy, it becomes difficult to purse a countercyclical monetary policy independent of exogenous shocks.

The only significant factors affecting the behavior of monetary policy in Saudi Arabia are the Federal Funds Rate (FFR) and the Trend variable. Indeed, the FFR appears to be the single most important determinant of the Saudi interest rate. Empirically, when the FFR changes by one unit, the Saudi interest rate changes by $0.85-0.92$ unit in the same direction. This is intuitive since the Saudi monetary authorities maintain a pegged exchange rate with the USD. As evident, monetary policy in Saudi Arabia responds very significantly to contemporaneous US interest rates, regardless of changes in the Saudi fundamentals- namely inflation and real output. However, the coefficient on the FFR suggests that the response of Saudi interest rate to changes in the FFR is less than one-to-one despite the fixed exchange rate regime. This is also evident in Figures A2 and A3 in the Appendix where the spread between the Saudi interest rate and the FFR widens at times and narrows at other times.

When including the FFR in the regressions, about 98 percent of the variations in Saudi interest rate become explainable. However, when the FFR is removed, the explanatory power of the model becomes dismal and the coefficients of the other factors become insignificant.

The Trend variable is negatively associated with the level of Saudi interest rate. Empirically the Saudi interest rate declines by 0.032 annually after controlling for other factors, including the FFR. This may be indicating modest monetary policy accommodation to structural changes, productivity growth, diversification efforts, and increasing financial intermediation. The effect of the Trend variable, while statistically significant at the 10 percent level, appears relatively small compared to that of the US Federal Funds Rate.

\section{Concluding Remarks and Future Research}

By calibrating and empirically estimating the Taylor-rule for the Saudi interest rate, it appears that the monetary authorities do not follow the rule suggested by Taylor (1993) in any strict way. The stance of monetary policy in the early period of analysis appears tighter than suggested by the rule. On the other hand, the Saudi interest rate appears lower in recent years than would be the case if the monetary authorities were applying the Taylor principles. With a few exceptions, however, the observed Saudi interest rate and that based on the Taylor-rule simulation seem to move in similar directions, notwithstanding the differences in their levels over the analysis period. This could mean important correlation between Saudi and US business cycles.

Empirically, the dynamics of the Federal Funds Rate is the most important factor explaining the variations in the Saudi interest rate. The Saudi monetary authorities, given the commitment to the Riyal/USD exchange peg, closely respond to US business cycles by adjusting nominal policy rates according to changes in the Federal Funds Rate. While tracking the FFR minimize speculations on the Saudi Riyal to maintain the peg, monetary authorities do not appear to respond in any significant way to deviations of the inflation rate and real output from their desired levels (the inflation objective and potential output).

However, the small negative response of the Saudi interest rate to the trend variable may mean some discretionary behavior to accommodate productivity growth and the increased need for financial intermediation. It may also imply modest attempts to aid industries improve their global competitiveness (by lowering the costs of financing). However, the magnitude of this response is relatively small compared to the reaction to the US monetary policy decisions.

An important extension of this work would be undertake counterfactual simulations by using the calibrated Taylor-rule interest rate as an independent variable determining dynamics in real output and inflation. Here, one would assess how much real output and inflation would have been if the Taylor model-based interest rate were to be the official interest rate of monetary policy. This could lead to important implications regarding the role of monetary policy in Saudi Arabia in smoothing domestic business cycles, maintaining macro stability, and accommodating necessary economic growth. 


\section{References}

Almounsor, A. (2010). Memorandum on recent economic developments in Saudi Arabia. Research and Statistics Department, Saudi Arabian Monetary Agency. Briefing Paper for Senior Management.

Asso, P., Khan G., \& Leeson, R. (2010). The Taylor rule and the practice of central banking. The Federal Reserve Bank of Kansas City, R. Working Paper 10-05.

Al-jasser, M., \& Banafe, A. (2000). Monetary policy instruments and procedures in Saudi Arabia. Bank for International Settlements, BIS policy note.

Al-jasser, M., \& Banafe, A. (2006). Monetary policy transmission mechanism in Saudi Arabia. Bank for International settlement, BIS paper No 35.

Debabrata, P., \& Kapur, M. (2012). Alternative monetary policy rules for India. International Monetary Fund, Working Paper B/12/118.

Filardo, A., Ma, G., \& Mihaljek, D. (2011). Exchange rate and monetary policy frameworks in EMEs. Bank for International Settlements, BIS paper No. 57.

Glarida, R., Gali, J., \& Gertler, M. (2000). Monetary policy rules and macroeconomic stability: Evidence and some theory. The Quaterly Journal of Economics.

Helmi, M. (2011). Monetary policy rules in the MEMA countries: Issues and evidence. International Journal for Social Sciences and Humanity Studies, 3(2).

Hofmann, B., \& Bogdanova, B. (2012). Taylor rules and monetary policy: A global great deviation. BIS Quarterly Review.

Hamalainen, N. (2004). A survey of Taylor-type monetary policy rules. Department of Finance. Working Paper 2004-02.

Judd, J., \& Rudebusch, G. (1998). Taylor's rule and the Fed:1970-1997. FRBSF Economic Review, 3.

Kafer, B. (2014). The Taylor rule and financial stability: A literature review with application for the Euro zone. University of Kassel, Department of Economics, Germany. Joint Discussion Paper No 30-2014.

Kindall, R., \& Ng, T. (2013). Estimated Taylor ruels updated for the post-crisis period. Reserve Bank of New Zealand Analytical Notes, AN2013/04, Reserve Bank of New Zealand.

Kozicki, S. (1999). How useful are Taylor rules for monetary policy? Federal Reserve Bank of Kansas City. Economic Review.

Malik, W., \& Ahmed, A. (2010). The Taylor rule and macroeconomic performance in Pakistan. The Pakistan Development Review, 37-56.

Markov, N., \& Nitschka, T. (2013). Estimating Taylor rules for Switzerland: Evidence from 2000 to 2012. Swiss National Bank Working Paper 2013-8.

Ncube, M., \& Tshuma, M. (2010). Monetary Policy Conduct Based on Non-linear Taylor Rule: Evidence from South Africa. African Development Bank Group, Working paper No. 113.

Taylor, J. (1993). Discretion versus policy rules in practice. Carnegie-Rochester Conference Series on Public Policy 39. http://dx.doi.org/10.1016/0167-2231(93)90009-L 


\section{Appendix A}

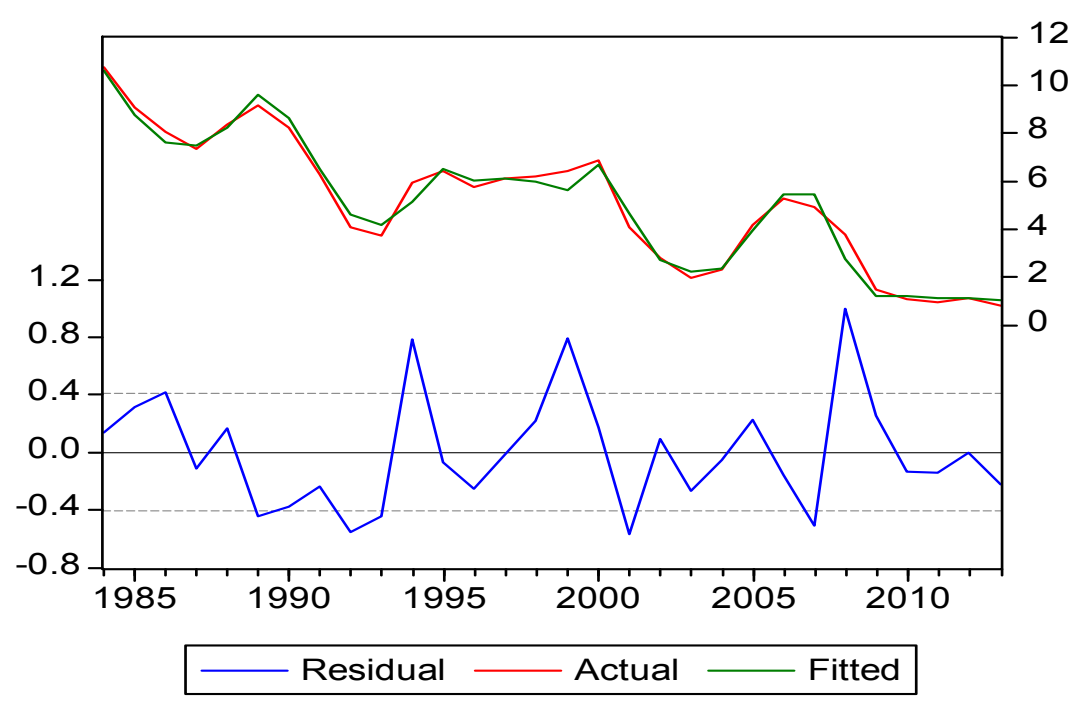

Figure A1. Fitted values and residuals

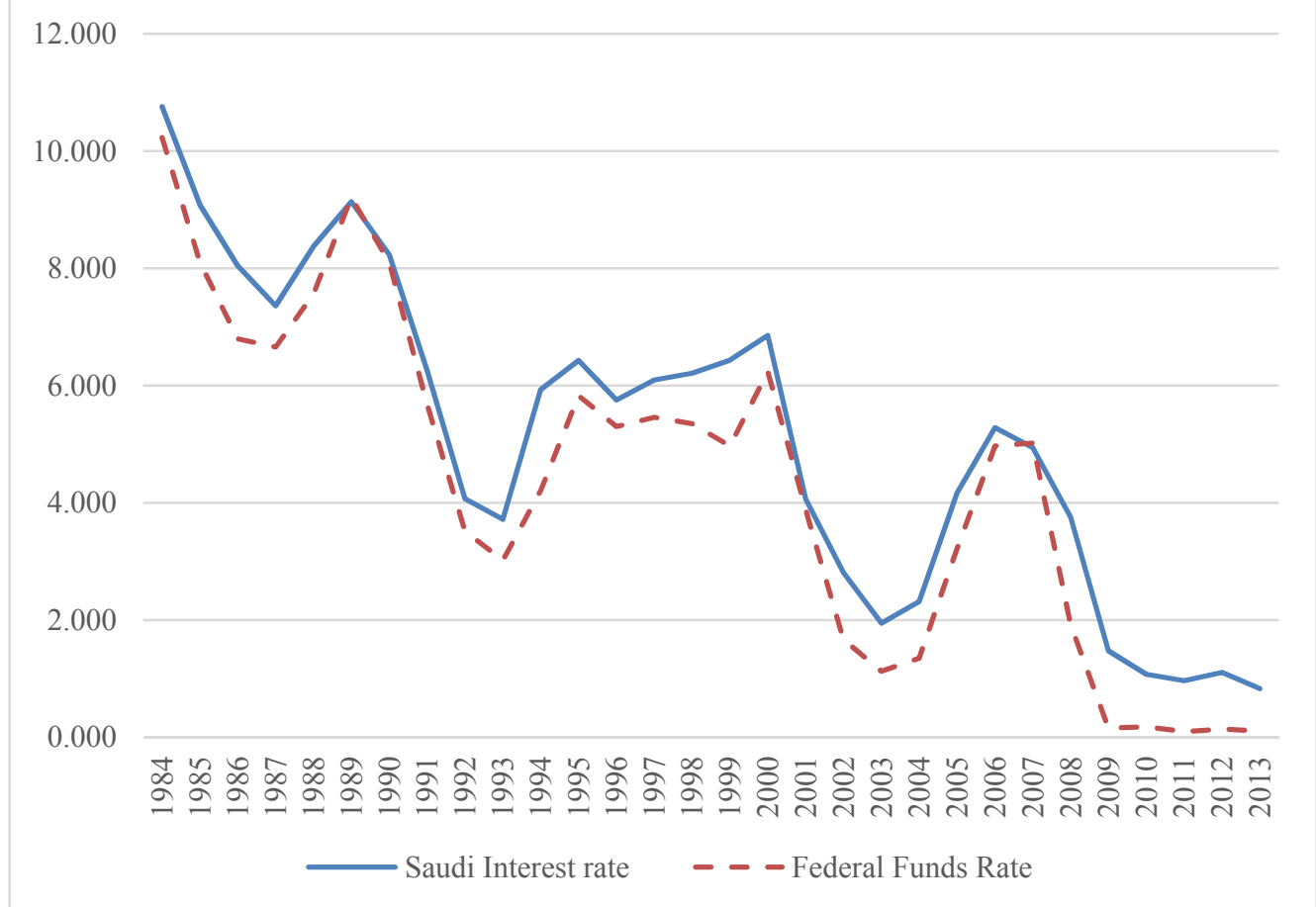

Figure A2. Saudi Versus US interest rates 


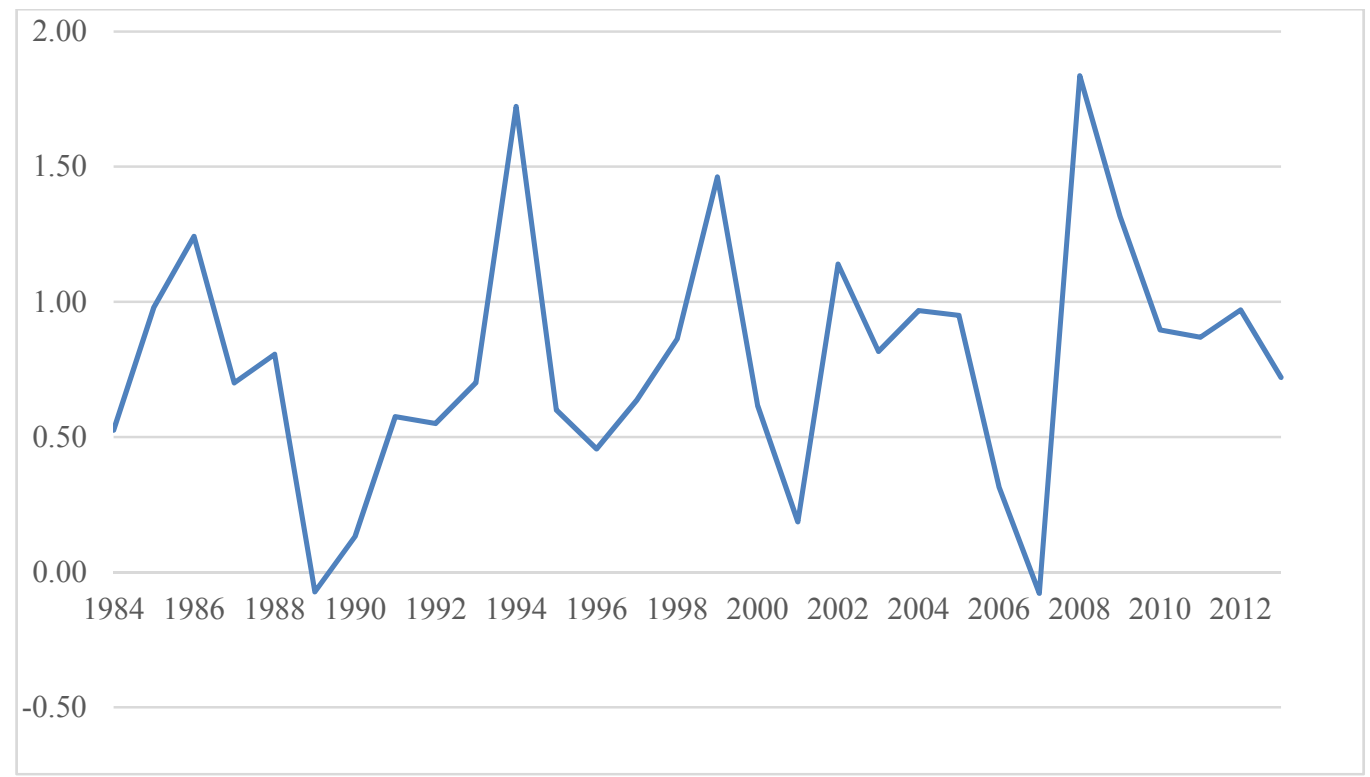

Figure A3. Spread between Saudi interest rate and the US federal funds rate (1984-2013)

\section{Copyrights}

Copyright for this article is retained by the author(s), with first publication rights granted to the journal.

This is an open-access article distributed under the terms and conditions of the Creative Commons Attribution license (http://creativecommons.org/licenses/by/3.0/). 